\title{
Effect of heat and homogenization on in vitro digestion of milk
}

\author{
Michael H. Tunick, ${ }^{*}$ Daxi X. Ren, ${ }^{*} †$ Diane L. Van Hekken, ${ }^{*}$ Laetitia Bonnaillie, ${ }^{*}$ Moushumi Paul, ${ }^{* 1}$ \\ Raymond Kwoczak, ${ }^{*}$ and Peggy M. Tomasula* ${ }^{2}$ \\ *Dairy and Functional Foods Research Unit, Eastern Regional Research Center, ARS, USDA, 600 E. Mermaid Lane, Wyndmoor, PA 19038 \\ †Institute of Dairy Science, College of Animal Sciences, Zhejiang University, Hangzhou 310029, P. R. China
}

\section{ABSTRACT}

Central to commercial fluid milk processing is the use of high temperature, short time (HTST) pasteurization to ensure the safety and quality of milk, and homogenization to prevent creaming of fat-containing milk. Ultra-high-temperature sterilization is also applied to milk and is typically used to extend the shelf life of refrigerated, specialty milk products or to provide shelfstable milk. The structures of the milk proteins and lipids are affected by processing but little information is available on the effects of the individual processes or sequences of processes on digestibility. In this study, raw whole milk was subjected to homogenization, HTST pasteurization, and homogenization followed by HTST or UHT processing. Raw skim milk was subjected to the same heating regimens. In vitro gastrointestinal digestion using a fasting model was then used to detect the processing-induced changes in the proteins and lipids. Using sodium dodecyl sulfate-PAGE, gastric pepsin digestion of the milk samples showed rapid elimination of the casein and $\alpha$-lactalbumin bands, persistence of the $\beta$-lactoglobulin bands, and appearance of casein and whey peptide bands. The bands for $\beta$-lactoglobulin were eliminated within the first $15 \mathrm{~min}$ of intestinal pancreatin digestion. The remaining proteins and peptides of raw, HTST, and UHT skim samples were digested rapidly within the first $15 \mathrm{~min}$ of intestinal digestion, but intestinal digestion of raw and HTST pasteurized whole milk showed some persistence of the peptides throughout digestion. The availability of more lipid droplets upon homogenization, with greater surface area available for interaction with the peptides, led to persistence of the smaller peptide bands and thus slower intestinal digestion when followed by HTST pasteurization but not by UHT processing, in which the denatured proteins may be more accessible to the di-

\footnotetext{
Received September 30, 2015.

Accepted February 24, 2016.

${ }^{1}$ Current address: Office of Outreach, Diversity, and Equal Opportunity, ARS, USDA, 1400 Independence Ave. SW, Washington, DC 20250.

${ }^{2}$ Corresponding author: Peggy.Tomasula@ars.usda.gov
}

gestive enzymes. Homogenization and heat processing also affected the $\zeta$-potential and free fatty acid release during intestinal digestion. Stearic and oleic acids were broken down faster than other fatty acids due to their positions on the outside of the triglyceride molecule. Five different casein phosphopeptide sequences were observed after gastric digestion, and 31 sequences were found after intestinal digestion, with activities yet to be explored. Processing affects milk structure and thus digestion and is an important factor to consider in design of foods that affect health and nutrition.

Key words: milk protein, milk lipid, HTST and UHT processing, casein phosphopeptides

\section{INTRODUCTION}

Milk is a complex food conferring several nutritional benefits due to its protein, fat, carbohydrate, vitamin, and mineral contents (Walzem et al., 2002). Because its shelf life is relatively short, heat treatments are used to preserve milk quality and destroy spoilage microorganisms and any pathogens, if present. The heat treatments used commercially by the dairy industry include HTST pasteurization (heating milk at a minimum of $72^{\circ} \mathrm{C}$ for $\geq 15$ s; FDA, 2013) and UHT sterilization (heating milk to $135-150^{\circ} \mathrm{C}$ in combination with a holding time; e.g., $140^{\circ} \mathrm{C}$ for $2.3 \mathrm{~s}$; Codex Committee on Milk and Milk Products, 1999). To prevent creaming, the milk is usually homogenized before the final heating step in HTST or UHT processing. The native milk fat globules, which are encapsulated by milk fat globule membrane (MFGM) and range from approximately 0.1 to $20 \mu \mathrm{m}$ with an average size of 3 to $5 \mu \mathrm{m}$, are reduced to about $1 \mu \mathrm{m}$ with homogenization (Michalski and Januel, 2006).

Increasing numbers of consumers have purchased raw milk, motivated by claims that it is more nutritious and more easily digested than heat-treated milk because the proteins are not denatured (Smith, 2010). However, depending on the temperature and length of treatment, heating of skim or whole milk above $65^{\circ} \mathrm{C}$ induces aggregation of the whey proteins but few protein interactions occur under HTST-pasteurization conditions. As 
the temperature approaches UHT-sterilization conditions, progressively more whey protein denaturation is observed and interactions between casein micelles and the denatured whey proteins, particularly $\beta-L G$, occur (Douglas et al., 1981; Farrell and Douglas, 1983; Corredig and Dalgleish, 1996a,b).

Contrary to claims by raw milk proponents, these conditions have been shown to result in no or only slight increases in protein digestibility (Farrell and Douglas, 1983; Claeys et al., 2013; Wada and Lönnerdal, 2014). Severe heat treatment not typically encountered in fluid milk production, such as in-can sterilization, may reduce protein digestibility by formation of lactulosyllysine at the lysine residues of the whey and casein proteins, cross-linking of proteins to form products such as lysinoalanine, and additional sulfide bonds (Wada and Lönnerdal, 2014), all of which inhibit the action of digestive enzymes.

Raw milk proponents have also stated that the reductions in lipid size and creation of protein-lipid complexes that disrupt the MFGM upon homogenization may harm health. The order of the heating and homogenization steps has been found to affect the association of proteins with the MFGM or lipids and their composition (Garcia-Risco et al., 2002; Michalski and Januel, 2006). Whether heating is conducted by a batch or continuous process is also a factor. Batch heating of nonhomogenized whole milk between 65 and $75^{\circ} \mathrm{C}$ shows binding of $\alpha$-LA and $\beta-\mathrm{LG}$ to the MFGM proteins, independent of length of treatment. With heating of milk to $85^{\circ} \mathrm{C}, \beta$-LG preferentially binds to the MFGM proteins, with very little micellar and mostly $\kappa-C N$ adsorbed to the MFGM. In HTST- and UHT-treated milk samples, more $\beta$-LG is bound to the MFGM proteins than $\alpha$-LA, which is attributed to the differences in temperature and use of these continuous methods.

Homogenization of whole milk followed by heat processing decreases the size of the fat globules and increases their total surface area and their numbers (Lee and Sherbon, 2002). The combination of heat and homogenization can result in even smaller droplet sizes compared with those from homogenization alone (Michalski and Januel, 2006). Adhesion of casein micelles or their fragments to the fat globule membrane is observed after homogenization but whey proteins are only observed on the membrane if the milk is heated before or following homogenization with no increase in the amount of casein upon heating (Lee and Sherbon, 2002). Denatured whey proteins attach to the adhered casein and MFGM proteins by disulfide bonds (Michalski and Januel, 2006). Few studies have been conducted to examine the effect of homogenization and heating on digestibility of milk (Michalski and Januel, 2006) but, as discussed in Claeys et al. (2013), smaller lipid droplet sizes would conceivably favor lipolysis, increasing the bioavailability of the fatty acids.

Few studies of the digestibility of milk have included physical methods such as particle size distribution, even though structural changes occur in the milk fat globules and proteins. Ye et al. (2011) and Gallier et al. (2012) showed the usefulness of this technique to follow the sizes of milk fat globules and aggregated proteins of bovine native milk during simulated digestion. The applicability of this technique for comparing changes in the sizes of the proteins and fats in between unprocessed and processed milk has not yet been demonstrated.

Another area of interest in studies of milk digestion is release of casein phosphopeptides (CPP), which are phosphorylated $\mathrm{CN}$-derived peptides that can be released through enzymatic hydrolysis of $\alpha_{\mathrm{S}^{-}}, \alpha_{\mathrm{S} 2^{-}}$, and $\beta-\mathrm{CN}$ during digestion. These peptides form soluble complexes with calcium and other minerals, allowing them to be absorbed through the intestinal wall at $\mathrm{pH}$ levels that would otherwise cause them to precipitate (Miquel et al., 2005). The presence of CPP during intestinal digestion of milk and variations due to type of processing may have implications on the bioavailability of minerals.

The effects of processes such as homogenization and heating of milk on gastrointestinal digestion and the effects on human health remain unclear. In this study, we subjected skim and whole fat milk to the individual homogenization or heating processes of HTST pasteurization and UHT sterilization and then in combination to examine the resistance of casein, whey, and milk fats to the effects of gastrointestinal digestion using a fasting model. The CPP arising from casein hydrolysis, $\zeta$-potential, and free fatty acid release were also monitored.

\section{MATERIALS AND METHODS}

\section{Samples and Reagents}

Fresh raw bovine milk was obtained from a local dairy farm, stored overnight at $4^{\circ} \mathrm{C}$, and then skimmed or standardized to $3.25 \%$ (wt/wt) fat content. One-liter portions underwent homogenization at $60^{\circ} \mathrm{C}$ (Universal Pilot Plant, Waukesha Cherry-Burrell, Philadelphia, PA) and (or) HTST pasteurization at $72^{\circ} \mathrm{C}$ for $15 \mathrm{~s}$, and UHT processing at $135^{\circ} \mathrm{C}$ for $2 \mathrm{~s}$ in an Armfield model FT74P/T HTST/UHT (Armfield Inc., Denison, IA) plate-and-frame continuous pasteurizer (Tomasula and Kozempel, 2004) and were then stored at $4^{\circ} \mathrm{C}$. Fresh sample was used within $1 \mathrm{~d}$ and processed samples 
were used in $<3 \mathrm{~d}$. The abbreviations used throughout the text to define the milk samples are as follows: $\mathbf{R}$ $=$ raw unprocessed milk, $\mathbf{R S}=$ raw skim milk, $\mathbf{R W}=$ raw whole milk, $\mathbf{H}=$ homogenized milk, $\mathbf{P}=$ HTSTpasteurized milk, SP = HTST-pasteurized skim milk, $\mathbf{H P}=$ homogenized and HTST-pasteurized milk, SU $=$ UHT-processed skim milk, and $\mathbf{H U}=$ homogenized and UHT-processed milk.

Fat, lactose, and protein were determined by a MilkoScan Minor (Foss, Eden Prairie, MN). Pepsin from porcine gastric mucosa (P7000; $250 \mathrm{U} / \mathrm{mg}$ of solid), porcine bile extract (B8631), and porcine pancreatin (P1750; $4 \times$ USP) were purchased from Sigma-Aldrich Corp. (St. Louis, MO). All other chemicals were of analytical grade and were purchased from Sigma-Aldrich unless specified otherwise.

\section{In Vitro Digestion}

Eight samples from each homogenization or combination of homogenization and heat treatments were digested. The in vitro gastric digestion model simulating the fasting state in humans based on Gallier et al. (2012) was used with some modifications. One hundred milliliters of each of the processed samples (RW, RS, $\mathrm{H}, \mathrm{P}, \mathrm{HP}, \mathrm{HU}, \mathrm{SP}$, or SU milk) was mixed with $50 \mathrm{~mL}$ of a simulated gastric fluid (SGF), which was prepared by dissolving $2.0 \mathrm{~g}$ of $\mathrm{NaCl} / \mathrm{L}, 7 \mathrm{~mL}$ of $\mathrm{HCl} / \mathrm{L}$, and $3.2 \mathrm{mg}$ pepsin/L at $\mathrm{pH} 1.2$ (US Pharmacopeia, 2012) and acidifying to $\mathrm{pH} 1.5$ with $6 \mathrm{M} \mathrm{HCl}$ in a $37^{\circ} \mathrm{C}$ shaking water bath (model OLS200, Grant Instruments, Shepreth, UK) at $95 \mathrm{rpm}$. Four 5 -mL aliquots were collected after $0,5,15,30$, and 60 min of digestion for particle size and other analyses.

Simulated intestinal fluid (SIF) was prepared with $6.8 \mathrm{~g}$ of $\mathrm{K}_{2} \mathrm{HPO}_{4} / \mathrm{L}$ and $77 \mathrm{~mL}$ of $0.2 \mathrm{M} \mathrm{NaOH} / \mathrm{L}$ and adjusted to $\mathrm{pH} 6.8$ (US Pharmacopeia, 2012). After the $1 \mathrm{~h}$ of gastric digestion of the raw and processed milk samples, in vitro intestinal digestion under simulated intestinal fasting conditions was carried out in the $37^{\circ} \mathrm{C}$ bath using a procedure similar to that of Gallier et al. (2012). The digested milk samples were mixed with the SIF (1:1) in a conical flask to a total volume of $200 \mathrm{~mL}$, the $\mathrm{pH}$ was adjusted to 7.0 , and bile extract $(5 \mathrm{mg} / \mathrm{mL}$ of SIF) was added. Pancreatin $(1.6 \mathrm{mg} / \mathrm{mL}$ of SIF) was then added, and four 5-mL aliquots were taken at 0,30 , 60, 90, and 120 min of simulated intestinal digestion, for particle size and other analyses. The $\mathrm{pH}$ was not adjusted during gastric or intestinal digestion.

\section{Protein Hydrolysis}

Processed and digested milk samples $(0.5 \mathrm{~mL})$ were placed directly from the freezer into boiling water for
$5 \mathrm{~min}$ to inactivate enzymes. Aliquots $(75 \mu \mathrm{L})$ were desalted using a Zeba Spin Desalting Column (ThermoScientific, Rockford, IL) and a ZIP Spin centrifuge (LW Scientific, Lawrenceville, GA) operating at 1,500 $\times g$ for $2 \mathrm{~min}$. Samples were prepared for SDS-PAGE and separated using a Criterion Cell and Basic PowerPac power supply according to manufacturer's instructions (Bio Rad, Hercules, CA); all gels, buffers, standards, and stains were obtained from BioRad. Briefly, samples were diluted 1:1 with tricine sample buffer containing $0.02 \%$ mercaptoethanol and boiled for $5 \mathrm{~min}$. Samples $(15 \mu \mathrm{L}$ for gastric digests, $20 \mu \mathrm{L}$ for intestinal digests, $10 \mu \mathrm{L}$ for Precision Plus Dual Xtra Standards) were placed in the wells of a 10 to $20 \%$ gradient Criterion Tris-Tricine gel paired with Tris-Tricine-SDS running buffer, and separated at $150 \mathrm{~V}$ for $65 \mathrm{~min}$. Gels were fixed for $30 \mathrm{~min}$ in acetic acid-methanol (10\%:40\%), stained for $30 \mathrm{~min}$ in Bio-Safe Coomassie stain, and destained in distilled water. Gels were scanned using a V700 Photo scanner (Epson America, Inc., Long Beach, CA) and protein profiles analyzed using densitometer software (Image Quant TL version 2003, GE Healthcare Bio-Sciences Corp., Piscataway, NJ).

\section{Particle Size Distribution}

The average particle sizes of the raw and processed milk samples, and then the digested samples as a function of time were determined by a laser-scattering particle size distribution analyzer (Horiba model \#LA-950V2, Kyoto, Japan). The samples were added dropwise to water in the measurement cell of the equipment until the $15 \%$ obscuration mark was reached. The volumeweighted mean diameter $\left(\mathbf{d}_{43}\right)$ and the surface-weighted mean diameter $\left(\mathbf{d}_{\mathbf{3 2}}\right)$ were calculated at each time point using the software provided with the instrument. The mean particle diameters were calculated as the average of duplicate measurements and the measurements were run in triplicate.

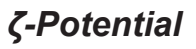

The $\zeta$-potentials of the raw, processed, and digested milk samples were measured using a Malvern Zetasizer Nano ZS instrument (Malvern Instruments Ltd., Malvern, UK) as described in Gallier et al. (2012). Triplicate measurements were made on at least 3 individual digestion experiments.

\section{Confocal Laser Scanning Microscopy}

The microstructures of the milk samples were studied using a TCS SPE confocal laser scanning microscope 
(Leica Microsystems, Buffalo Grove, IN) with a 100$\mathrm{mm}$ oil immersion objective lens. One hundred microliters of sample was vortexed with $6 \mu \mathrm{L}$ of Nile Red dye $(1 \mathrm{mg} / \mathrm{mL}$ in dimethyl sulfoxide, $1: 100 \mathrm{vol} / \mathrm{vol})$ and 6 $\mu \mathrm{L}$ of Fast Green FCF dye $(1 \mathrm{mg} / \mathrm{mL}$ in Milli-Q water, $1: 100 \mathrm{vol} / \mathrm{vol}$ ), and $7 \mu \mathrm{L}$ of the mixture was placed on a slide under a coverslip. Nile Red, which stained the fat, was excited with the 532 -nm laser and emission was captured from 550 to $650 \mathrm{~nm}$ using the Leica Acquisition Suite. Fast Green, which stained the protein, was excited with the $635-\mathrm{nm}$ laser and emission was captured from 655 to $755 \mathrm{~nm}$.

\section{Free Fatty Acid Release}

Five sample aliquots were titrated with $0.05 \mathrm{M} \mathrm{NaOH}$ until the $\mathrm{pH}$ reached 7.00, as measured by a 510 Series $\mathrm{pH} / \mathrm{mV} /{ }^{\circ} \mathrm{C}$ meter (Oakton Instruments, Vernon Hills, IL). The percentage of free fatty acids was calculated by multiplying milliliters by 0.04 .

\section{Fatty Acid Profiles}

The fatty acids in the milk samples were converted to methyl esters using a procedure based on Christie (2003). Each milk sample, weighing 100 to $125 \mathrm{mg}$, was dissolved in $2.5 \mathrm{~mL}$ of hexane (Fisher Scientific, Fair Lawn, NJ), and $100 \mu \mathrm{L}$ of sodium methoxide ( $25 \%$ by weight in methanol) was added. After 5 min of shaking by inversion, $5 \mu \mathrm{L}$ of glacial acetic acid (J. T. Baker, Phillipsburg, NJ) was added, followed by $1.0 \mathrm{~g}$ of anhydrous $\mathrm{CaCl}_{2}$ (Mallinckrodt Specialty Chemicals, Paris, $\mathrm{KY})$. After $1 \mathrm{~h}$, the liquid was centrifuged at $700 \times g$ for 2 to $3 \mathrm{~min}$, and the lipid supernatant was pipetted into a $2-\mathrm{mL}$ vial with a screw cap containing a Teflonfaced silicone septum (Supelco, Bellefonte, PA). The hexane was evaporated under nitrogen and $1.0 \mathrm{~mL}$ of ethyl acetate (Burdick \& Jackson, Muskegon, MI) was added. An autosampler injected $1.0 \mu \mathrm{L}$ into a HP 6980 gas chromatograph with flame-ionization detection (Hewlett-Packard, Santa Clara, CA) and an SP-2380 fused silica capillary column $(60 \mathrm{~m} \times 0.25 \mathrm{~mm}$; Supelco). The carrier gas was He flowing at $1.0 \mathrm{~mL} / \mathrm{min}$, the injector temperature was $200^{\circ} \mathrm{C}$, the detector was $220^{\circ} \mathrm{C}$, and the oven temperature was initially $100^{\circ} \mathrm{C}$ and after $5 \mathrm{~min}$ was increased to $200^{\circ} \mathrm{C}$ at $20^{\circ} \mathrm{C} / \mathrm{min}$. The chromatographic peaks were integrated with the instrument's software to obtain percentages of fatty acids in the fat. The reference standards were even-numbered C4:0 to C24:0 methyl esters (along with C15:0 and C17:0) and conjugated methyl linoleate (GLC448 and UC-59M, respectively; Nu-Chek Prep, Elysian, MN).

\section{Casein Phosphopeptide Identification}

Following the procedure of Miquel et al. (2005), 0.3 $\mathrm{g}$ of lyophilized defatted milk sample was weighed into a $50-\mathrm{mL}$ centrifuge tube and dissolved in $10 \mathrm{~mL}$ of 1 $M$ Tris, $\mathrm{pH}$ 8. While the mixture was being stirred, 20 $\mathrm{mL}$ of $10 \%$ (wt/vol) $\mathrm{CaCl}_{2}$ was added, followed by slow addition of $20 \mathrm{~mL}$ of $100 \%$ ethanol. The solution was centrifuged at $1,200 \times g$ for $30 \mathrm{~min}$ at $10^{\circ} \mathrm{C}$, and the supernatant decanted. Thirty milliliters of $50 \%$ ethanol was added and the precipitate was mixed by vortex to suspend and wash the pellet in the ethanol solution. The mixture was centrifuged again and the liquid decanted. Very small amounts of water were added and the mixture was frozen in liquid nitrogen and lyophilized in a weighed test tube. Once lyophilized, the tube was weighed again and the yield of CPP from $0.3 \mathrm{~g}$ of milk sample was noted.

Peptide extracts were separated by reversed-phase ultraperformance liquid chromatography (UPLC), injecting $4 \mu \mathrm{L}$ of sample into a Nano-Acquity UPLC (Waters, Milford, MA) equipped with a Symmetry C18 trap column $(5 \mu \mathrm{m}, 180 \mu \mathrm{m} \times 20 \mathrm{~mm}$, Waters $)$ for salt removal, concentration, and subsequent separation on an analytical nano-Acquity HSS T3, $1.8 \mu \mathrm{m}(75 \mu \mathrm{m} \times$ $150 \mathrm{~mm}$ ) column (Waters). Elution of the columns was achieved using a 40-min aqueous gradient of 5 to $40 \%$ acetonitrile $(0.1 \%$ formic acid $)$ at $400 \mathrm{~nL} / \mathrm{min}$. The UPLC effluent was directed to a quadrupole-time of flight analyzer (Q-TOF) Synapt G1 mass spectrometer (Waters) equipped with a Nano-Lock-Spray probe operated in positive mode. The mass spectrometer was controlled by MassLynk Software v. 4.1 (Waters) and data acquisition was achieved using a $\mathrm{MS}^{\mathrm{E}}$ method. The collision energy was set at $6 \mathrm{eV}$ (low energy, for intact peptide detection) and increased from 15 to $40 \mathrm{eV}$ (high energy, for peptide fragmentation) at an interval of $1 \mathrm{~s}$. The reference mass-lock electrospray was pumped at $450 \mathrm{~nL} / \mathrm{min}$ with an Acquity Auxiliary pump (Waters) with a solution containing 300 fmol of Glu-fibrinopeptide $\left([\mathrm{M}+2 \mathrm{H}]^{+}=785.8426\right)$ and $0.1 \%$ formic acid in $25 \%$ acetonitrile, and sampled at intervals of $30 \mathrm{~s}$ to calibrate the TOF analyzer. Before the injection of each set of samples, the TOF analyzer calibration was checked for mass accuracy within 3 ppm with the fragmented ions ( $30 \mathrm{~V}$ collision energy) of the Glu-fibrinopeptide. The MS data were queried against a milk proteins database downloaded from UniProt Knowledgebase (http://www.uniprot.org/ help/uniprotkb). The search engine was ProteinLynk Global Server version 4.1 (Waters). Parameters for the database search were set as nondigestion enzyme, methionine oxidation, and phosphorylation at serine sites 


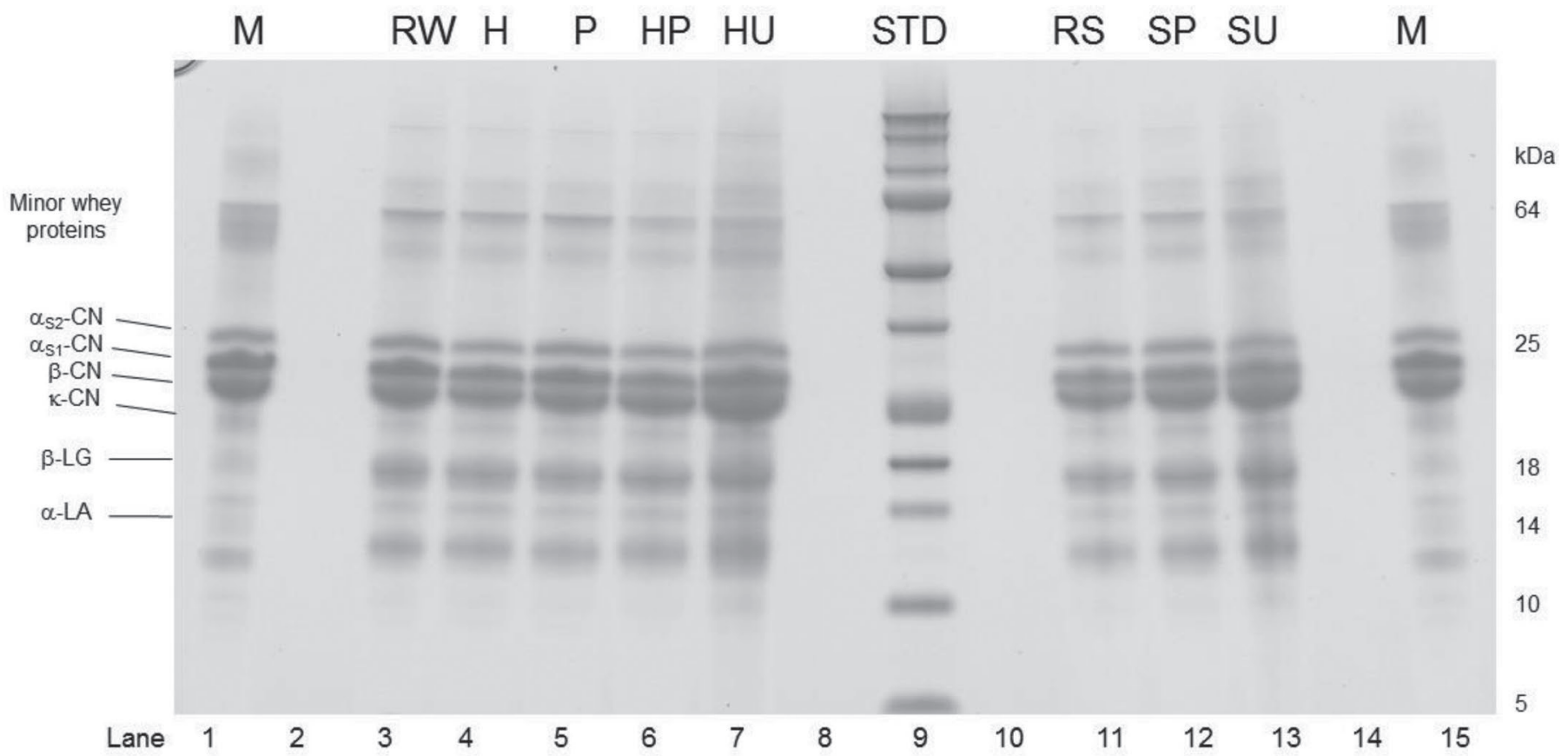

Figure 1. Sodium dodecyl sulfate-PAGE of processed milk samples before digestion. Lanes 1 and $15=$ milk standards $(\mathrm{M})$, lane $3=$ raw whole milk (RW), lane $4=$ homogenized raw whole milk $(\mathrm{H})$, lane $5=$ pasteurized whole milk $(\mathrm{P})$, lane $6=$ homogenized, HTST pasteurized whole milk (HP), lane $7=$ homogenized, UHT sterilized whole milk (HU), lane $9=$ molecular standard (STD), lane $11=$ raw skim milk (RS), lane 12 = HTST-pasteurized skim milk (SP), lane 13 = UHT skim milk (SU).

as variable modifications. Mass spectrometric data from milk samples were analyzed in duplicate. Peptide sequences that were observed in both MS runs of each sample were determined to be real. Peptide sequences were analyzed to determine which sequences occurred in each milk processing sample and then compared among processing methods. Sequences were also compared with known bioactive compounds to identify potential active CPP within each sample.

\section{Statistical Analyses}

The digestibility results were expressed as means \pm standard deviation of 3 replicates. The results were analyzed using ANOVA and the Tukey test $(P$-values $\leq 0.05)$. Statistical analyses were performed using SAS System 8c-Statistical Analysis System (version 9.1.3, 2003; SAS Institute Inc., Cary, NC)

\section{RESULTS AND DISCUSSION}

\section{Composition}

Raw milk contained 3.4 to $3.9 \%$ fat, 4.7 to $4.9 \%$ lactose, and 3.0 to $3.2 \%$ protein. The milk was standard- ized to 3.2 to $3.3 \%$ fat without affecting the lactose and protein contents. Skim milk contained no detectable fat, $4.9 \%$ lactose, and 3.1 to $3.2 \%$ protein.

\section{Protein Digestion}

Sodium dodecyl sulfate-PAGE of the processed milk samples before gastrointestinal digestion are compared with raw whole (RW) and raw skim (RS) milk samples in Figure 1. Whole milk samples that were homogenized at $60^{\circ} \mathrm{C}$ but not pasteurized $(\mathrm{H}), \mathrm{HTST}$ pasteurized $(\mathrm{P})$, or homogenized and then pasteurized (HP), showed similar casein and whey band patterns and intensities compared with RW. For HU, the overall smearing of the bands, not observed for the other treatments, could be indicative of disulfide bond interactions among the proteins (Wada and Lönnerdal, 2014). The bands for the pasteurized skim milk sample (SP) were similar in intensity to those for RS. The bands for the SU sample also showed some smearing and possible disulfide bond interactions.

Sodium dodecyl sulfate-PAGE for the whole and skim processed milk samples subjected to gastric and intestinal digestions are shown in Figures $2 \mathrm{a}$ and $2 \mathrm{~b}$, respectively. The in vitro gastric digestions were initiated by addition of SGF and pepsin at 0 min (lane 1 for 
a)

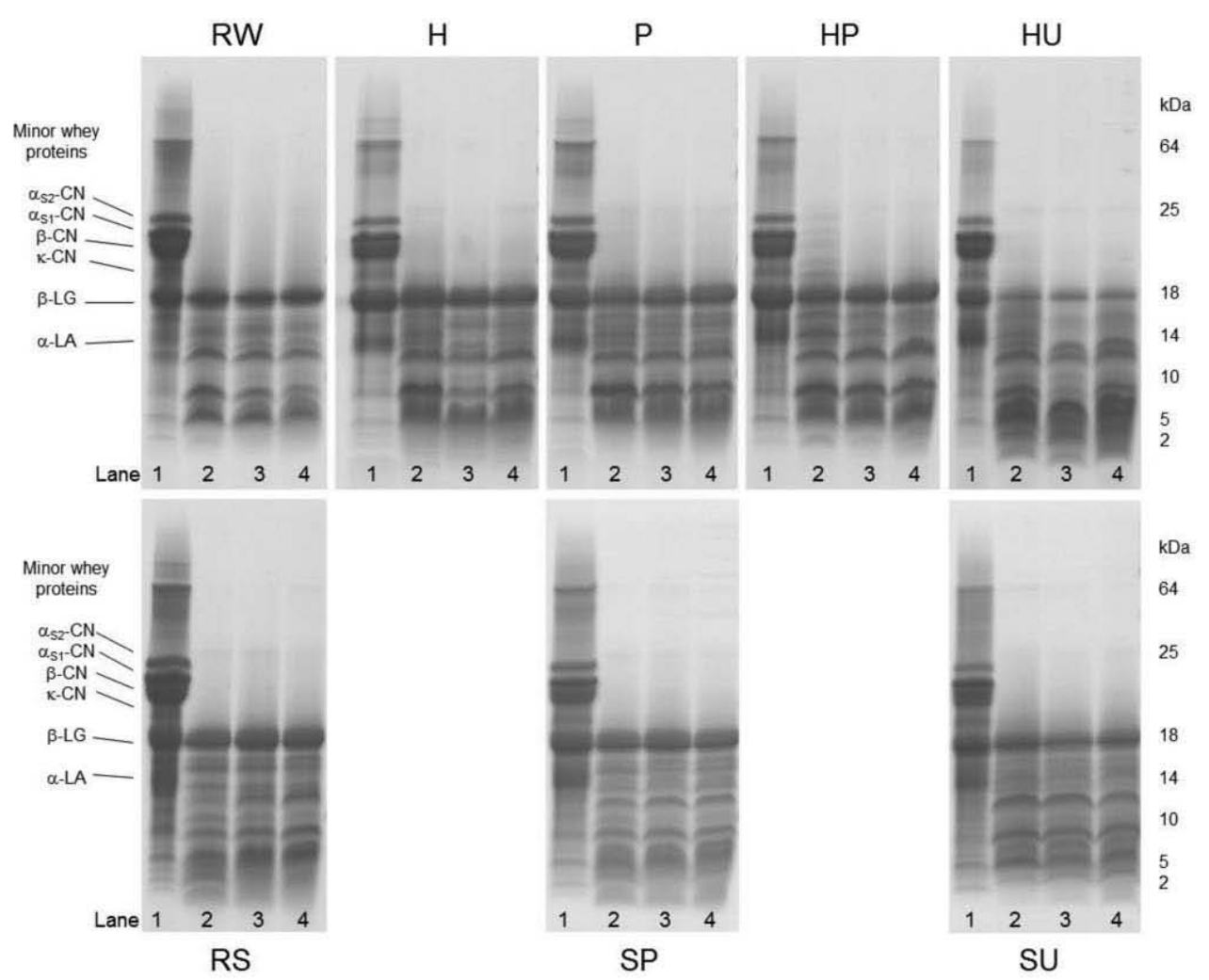

b)

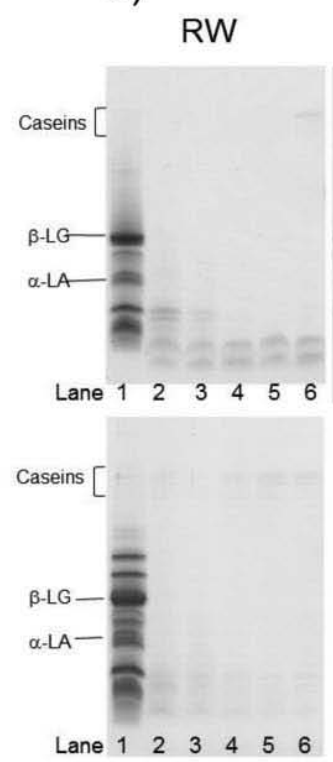

RS
$\mathrm{H}$

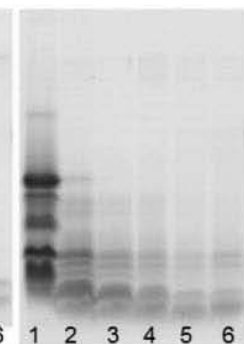

$\begin{array}{llllll}1 & 2 & 3 & 4 & 5 & 6\end{array}$

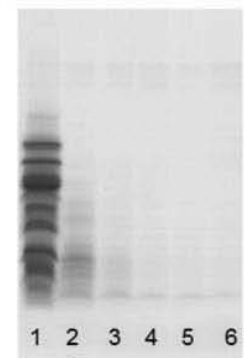

SP
HP
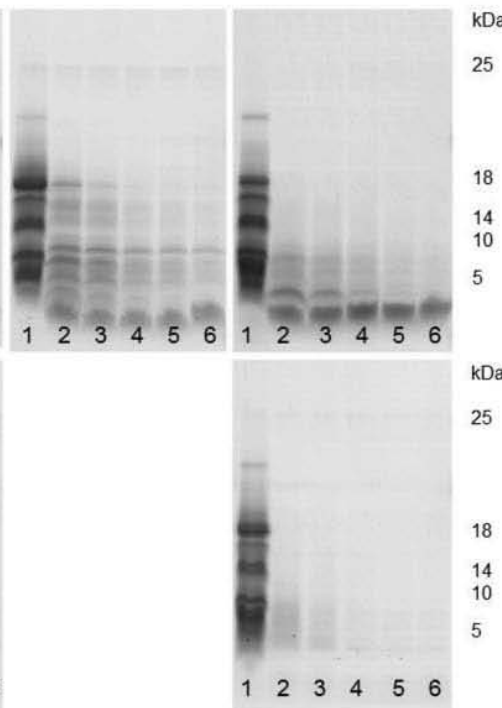

SU

Figure 2. (a) Sodium dodecyl sulfate-PAGE of processed milk samples during gastric digestion. Lane 1 of each series shows the processed sample from Figure 1 after the initiation of gastric digestion. Lane 1 time $=0$, lane 2 time $=15$ min, lane 3 time $=30$ min, lane 4 time $=60$ min . (b) Sodium dodecyl sulfate-PAGE of processed milk samples during intestinal digestion. Lane 1 of each series shows the processed sample from lane 4 of panel (a) upon initiation of intestinal digestion. Lane 1 time $=0$, lane 2 time $=15$ min, lane 3 time $=30$ min, lane 4 time $=60$ min, lane 5 time $=90 \mathrm{~min}$, and lane 6 time $=120 \mathrm{~min} . \mathrm{RW}=$ raw whole milk, $\mathrm{H}=$ homogenized, $\mathrm{P}=\mathrm{HTST}$ pasteurized, HP $=$ homogenized and HTST pasteurized, $\mathrm{HU}=$ homogenized and UHT pasteurized. $\mathrm{RS}=$ raw skim milk; SP $=$ HTST-pasteurized skim milk; SU = UHT-processed skim milk. 
each processing treatment) and ended at $60 \mathrm{~min}$ (lane 4 for each processing treatment). The intestinal digestions, with addition of the bile salts and pancreatin, were then initiated at $0 \mathrm{~min}$ (lane 1 ) and terminated 120 min later (lane 6).

In the first $15 \mathrm{~min}$ of gastric digestion of the RW, $\mathrm{H}$, or RS samples (lane 2; Figure 2a), the band intensities for intact $\mathrm{CN}, \alpha-\mathrm{LA}$, and the minor whey proteins faded and band intensities for the peptides of $\mathrm{CN}$ and whey (approximately $<10 \mathrm{kDa}$ ) became apparent. $\beta$-Lactoglobulin for all samples was resistant to pepsin digestion over the entire $60 \mathrm{~min}$. The P, HP, and HU samples also showed lighter band intensities for digestion of the $\mathrm{CN}$ and minor whey proteins and were difficult to distinguish from RW, even though RW was not processed. However, $\mathrm{H}$ and $\mathrm{HP}$ bands at $<10$ $\mathrm{kDa}$ appeared darker throughout the digestion period of 60 min than those for the P and SP samples, indicating possible stabilization of the peptides with lipid due to homogenization. Compared with the other samples, the HU and SU samples showed more faded bands for $\beta-\mathrm{LG}$ and denser band intensities for the $\mathrm{CN}$ and whey peptides in the region below $5 \mathrm{kDa}$, with $\mathrm{HU}$ showing darker bands.

Upon intestinal digestion, the bands for $\beta$-LG (lane 2 , Figure $2 b$ ) faded with trypsin/chymotrypsin digestion for the RW and RS samples in the first $15 \mathrm{~min}$ but were still apparent for $\mathrm{H}$ until 30 min of digestion. The bands for the peptide fragments for RS also faded, but there was some persistence of these bands over the next $2 \mathrm{~h}$ for the RW samples, as indicated by the lighter bands at $<10 \mathrm{kDa}$. The $\mathrm{H}$ sample showed much darker bands, with more peptides generated because of the disruption of the casein micelles and the fat globules and the subsequent creation of lipid-peptide compounds (Michalski and Januel, 2006).

The SP and SU samples showed about the same banding pattern up to about 30 min of intestinal digestion with slightly more intensity in the bands noted for SP. $\beta$-Lactoglobulin, which was not digested during gastric digestion, was digested within 15 min of intestinal digestion. In contrast to the RS, SP, and SU samples, the RW, H, P, and HP samples exhibited faded bands of $<18 \mathrm{kDa}$ from gastric digestion, with many of the bands persisting throughout the 2-h digestion period. $\beta$-Lactoglobulin in the $\mathrm{P}$ and HP samples persisted for about 30 min but was digested in $15 \mathrm{~min}$ in the RW, $\mathrm{H}$, and HU samples. Overall, HP would seem to be the least digestible sample over the 2 -h period, based on the persistence and intensity of protein bands, and RW was the most digestible of the whole milk samples, as determined by in vitro testing.

\section{Particle Size Distribution}

The volume mean particle diameter, $\mathrm{d}_{43}$, which is more sensitive to large particles, and the surfaceweighted mean diameter, $\mathrm{d}_{32}$, which is more sensitive to small particles (Mun et al., 2007) of the whole and skim milk samples were determined before and during gastrointestinal digestion. Only results for whole milk are reported in Figures 3a and 3b, respectively. Initiation of gastric digestion through addition of $\mathrm{HCl}$ and pepsin for the RW milk and the processed samples (G0, Figure 3a) caused a marked increase in $d_{43}$ in the order $\mathrm{P}(159.0 \pm 0.1 \mu \mathrm{m})>\mathrm{HP}(122.2 \pm 1.8 \mu \mathrm{m})>\mathrm{RW}$ $(105.8 \pm 0.2 \mu \mathrm{m})>\mathrm{H}(92.5 \pm 25.0 \mu \mathrm{m})>\mathrm{HU}(30.7$ $\pm 3.0 \mu \mathrm{m})$. Before $\mathrm{HCl}$ and pepsin addition, initial $\mathrm{d}_{43}$ (labeled as original on the figure) for the samples ranged between a low of $7.0 \mu \mathrm{m}$ for P milk to a high of $8.5 \mu \mathrm{m}$ for RW milk samples. The HU sample exhibited a much smaller increase in $\mathrm{d}_{43}$ because UHT processing results in denaturation of the proteins, which inhibits aggregation (Douglas et al., 1981; Farrell and Douglas, 1983). Within the first 15 min of gastric digestion, $\mathrm{d}_{43}$ for all samples was reduced to approximately $21.0 \mu \mathrm{m}$, and after $60 \mathrm{~min}$ to $11.2 \mu \mathrm{m}$. The particle sizes upon initiation of gastric digestion were significantly larger $(P<0.05)$ for skim milk than for whole milk with $\mathrm{d}_{43}$ decreasing in the order SP $(210.3 \pm 10.4 \mu \mathrm{m})>$ RS $(195.0 \pm 3.3)>\mathrm{SU}(97.1 \pm 8.2 \mu \mathrm{m})$. The initial particle sizes were RS $(1.30 \mu \mathrm{m})$, SP $(1.05 \mu \mathrm{m})$, and SU $(1.8 \mu \mathrm{m})$. Smaller particle sizes are reported for the whole milk samples because of the inclusion of the fat globules, which decreases the value of $\mathrm{d}_{43}$ in the calculations.

Upon initiation of intestinal digestion (I0, Figure 3a), particle size was further reduced from the values at the end of gastric digestion because of the action of the bile extract and pancreatin. For the whole milk samples only, $\mathrm{d}_{43}$ began to increase as intestinal digestion progressed. This effect was more easily viewed using the surface-weighted mean diameter, $\mathrm{d}_{32}$, as shown in Figure $3 \mathrm{~b}$, because of the smaller particles encountered in intestinal digestion. The particle diameters of the samples increased for R, H, P, HP, and HU from 8.2, $7.9,8.1,9.1$, and $5.0 \mu \mathrm{m}$ to $10.0,9.4,9.9,10.6$, and 8.7 $\mu \mathrm{m}$, respectively, with the largest gain of $3.7 \mu \mathrm{m}$ in diameter noted for HU. In comparison, increases in particle diameter were not noted for the skim milk samples (RS, SP, and SU), which were 4.4, 4.4, and $3.9 \mu \mathrm{m}$, respectively. As noted by Gallier et al. (2012), the fat globules destabilized as intestinal digestion progressed, eventually coalescing, which would present as an increase in the mean particle sizes at the end of digestion. 
a)

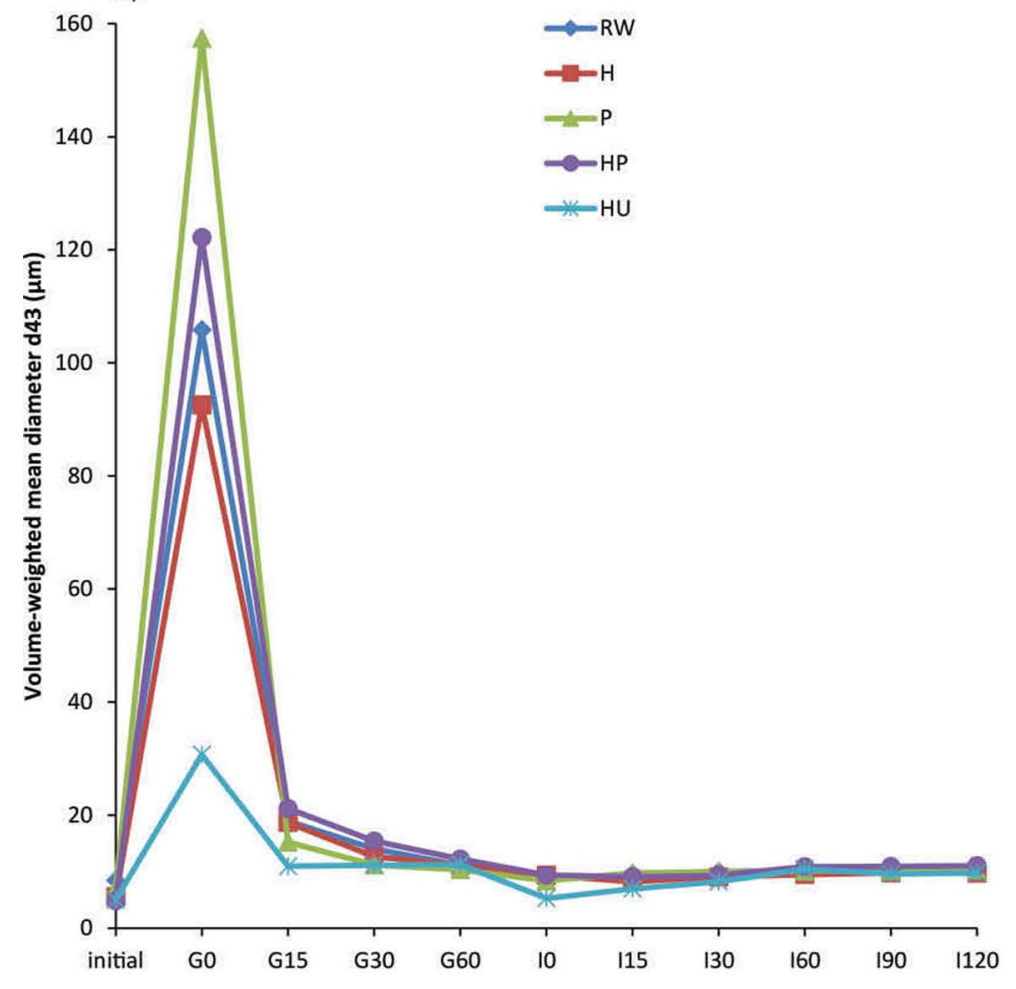

b)

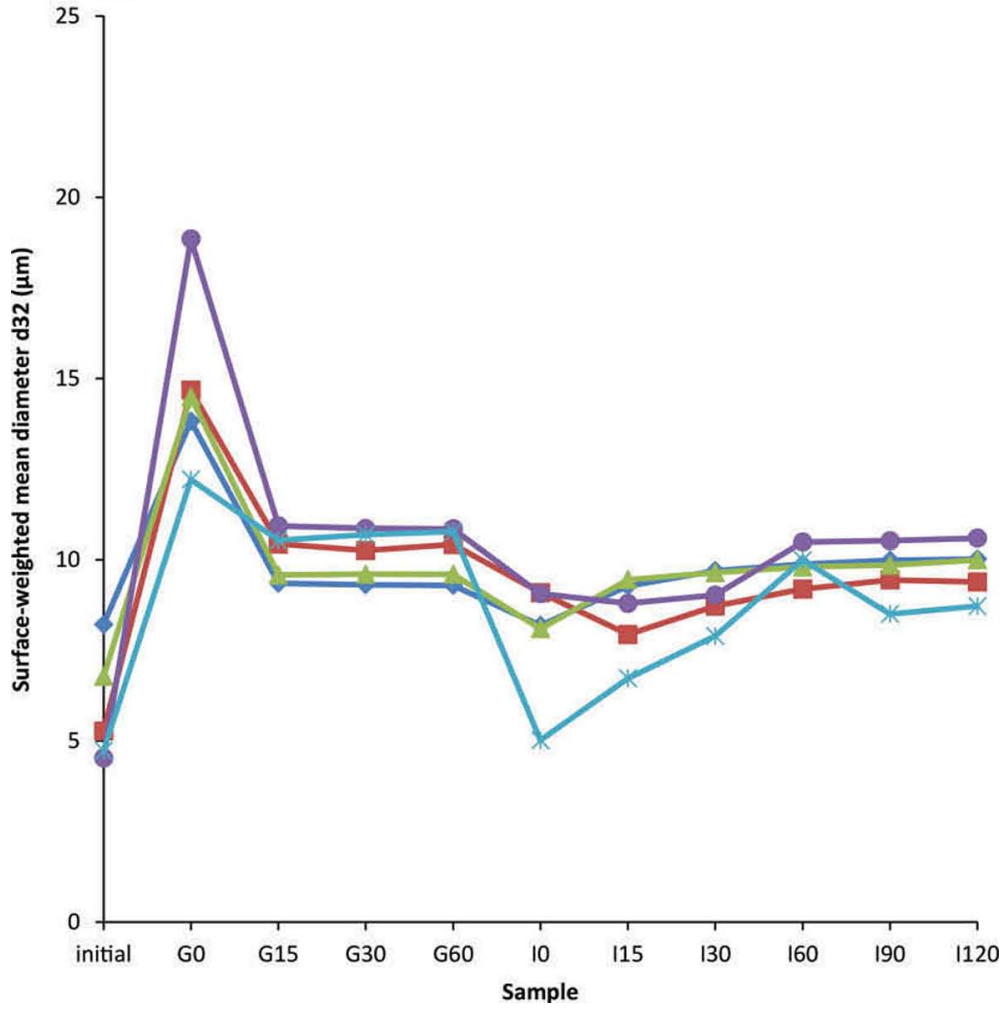

Figure 3. (a) Volume-weighted mean diameters $\left(\mathrm{d}_{43}\right)$ and (b) surface-weighted mean diameters $\left(\mathrm{d}_{32}\right)$ of whole milk and digested whole milk from before digestion (initial), during gastric digestion (from G0, before adding pepsin, to G60, 60 min after adding pepsin), and during intestinal digestion (from I0, before adding pancreatin, to I120, 120 min after adding pancreatin). RW = raw whole milk, $\mathrm{H}=$ homogenized, $\mathrm{P}=$ HTST pasteurized, HP $=$ homogenized and HTST pasteurized, HU = homogenized and UHT pasteurized. Color version available online. 


\section{$\zeta$-Potential}

The $\zeta$-potentials of the samples before and during digestion are shown in Figure 4 (whole milk) and Figure 5 (skim milk). Before addition of the SGF, $\mathrm{pH}$ adjustment to 1.5 , and addition of pepsin, the $\zeta$-potential of raw whole milk was $-34.1 \mathrm{mV}$ at near neutral $\mathrm{pH}$, a result similar to the $-35.5 \mathrm{mV}$ found by Gallier et al. (2012). Compared with raw whole milk, all of the processing treatments showed slightly lower $\zeta$-potential readings, reflecting the effect of the processing treatment. These showed as subtle differences in surface charges due to induced interactions between the proteins and the lipids; for example, in which the proteins adsorbed to the
MFGM or to the lipid droplets (Michalski and Januel, 2006). The higher value for raw whole milk accounts for the contributions of the casein aggregates and the unhomogenized milk fat. In comparison, the lowered values for the processed samples reflect protein interactions with the MFGM or lipids. When subjected to gastric conditions at $\mathrm{G}=0$, the surface charges became positive, increasing to $31.8 \mathrm{mV}$ because of the decrease in $\mathrm{pH}$ to 1.5 , below the isoelectric point of the proteins, resulting in their aggregation. The $\zeta$-potentials of the processed milk samples also became positive but, regardless of homogenization or heat treatment, clustered around $19 \mathrm{mV}$. As shown in Figure 5, the $\zeta$-potential for skim milk was lower than that for whole

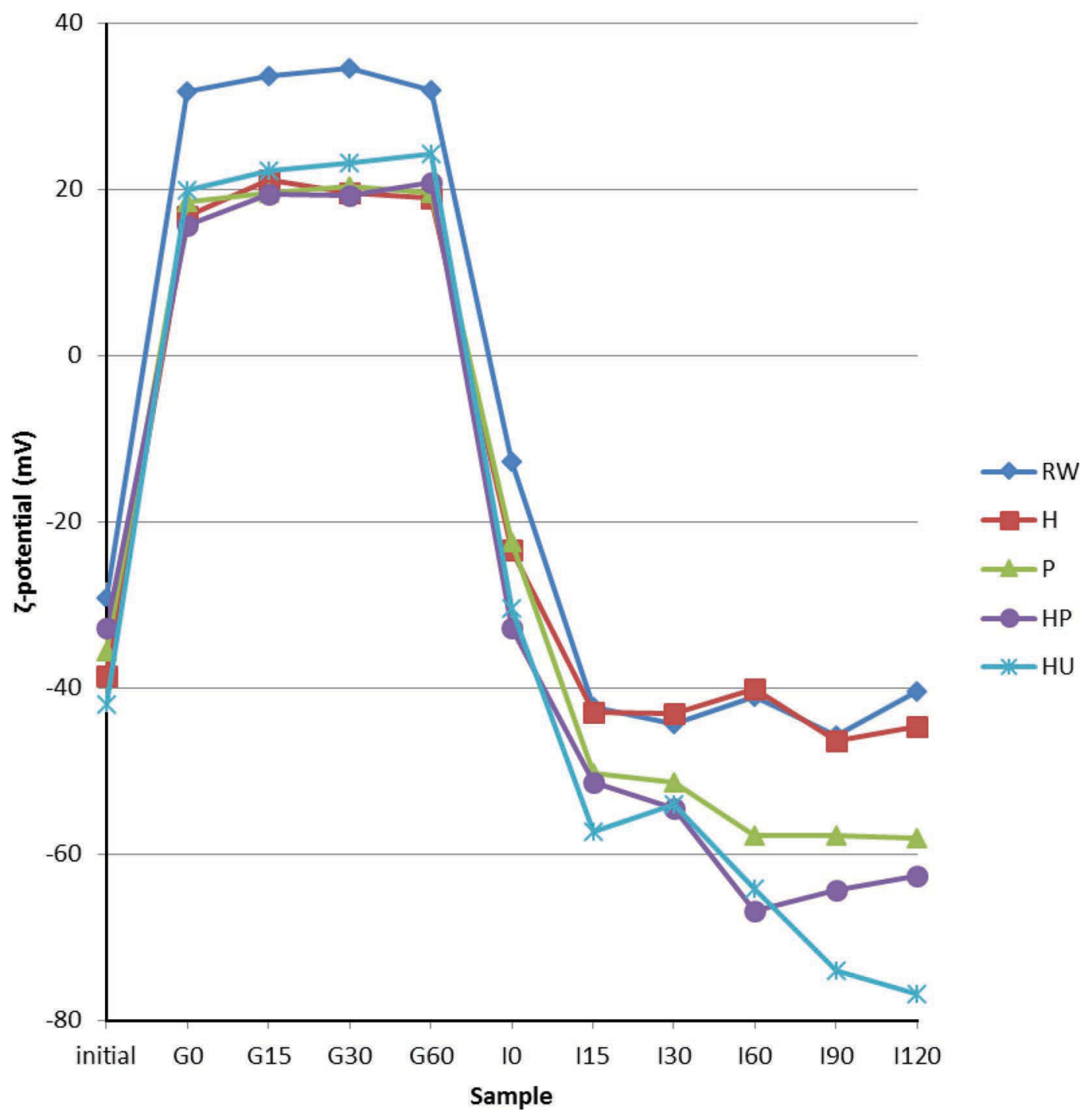

Figure 4. $\zeta$-Potential values of raw and processed whole milk before digestion (initial), during gastric digestion (from G0, before adding pepsin, to G60, 60 min after adding pepsin), and during intestinal digestion (from I0, before adding pancreatin, to I120, 120 min after adding pancreatin). RW = raw whole, $\mathrm{H}=$ homogenized, $\mathrm{P}=$ HTST pasteurized, $\mathrm{HP}=$ homogenized and HTST pasteurized, HU $=$ homogenized and UHT pasteurized. Color version available online. 


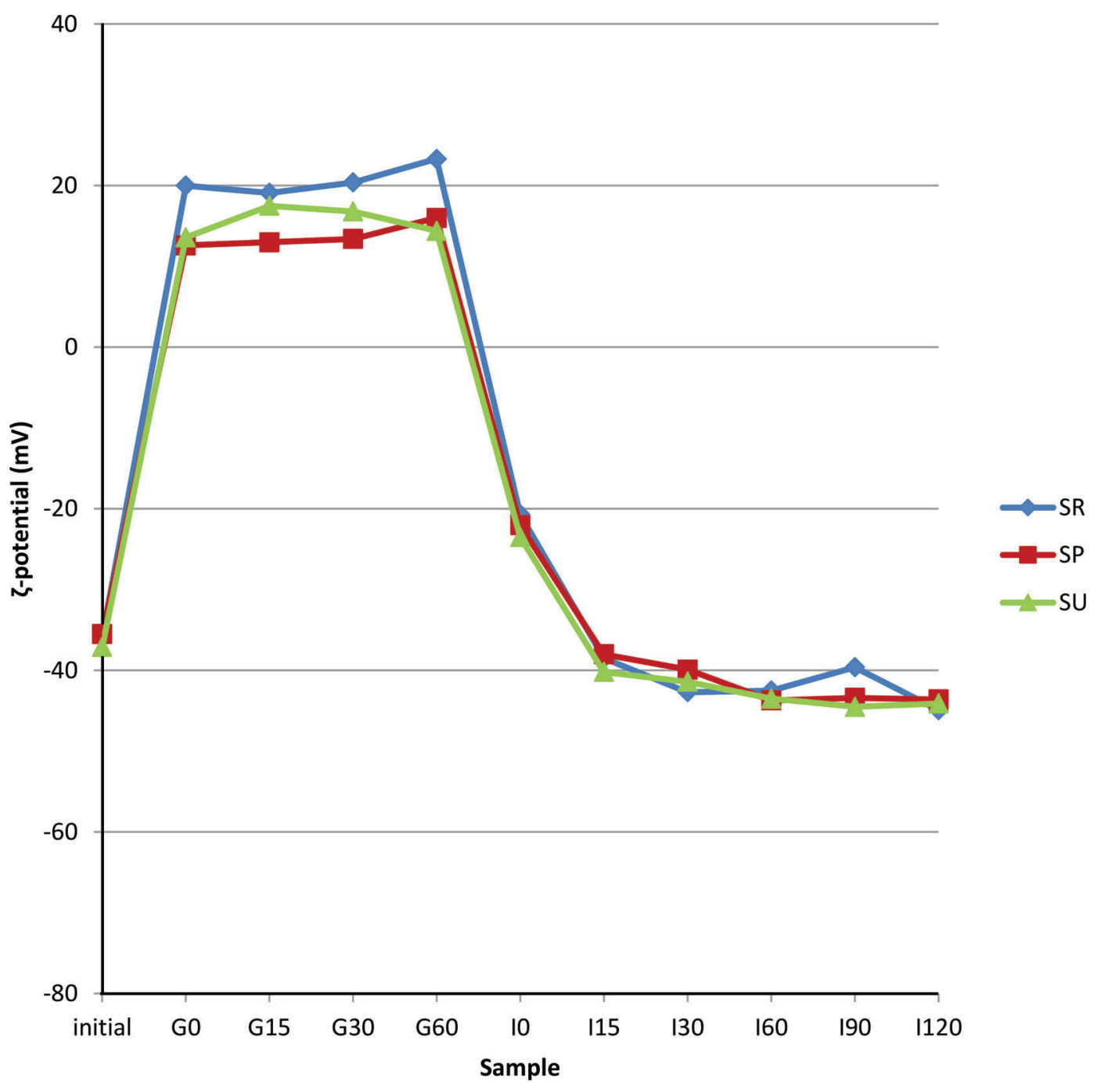

Figure 5. (5-Potential values of raw and processed skim milk before digestion (initial), during gastric digestion (from G0, before adding pepsin, to G60, 60 min after adding pepsin), and during intestinal digestion (from I0, before adding pancreatin, to I120, 120 min after adding pancreatin). $\mathrm{SR}=$ raw, $\mathrm{SP}=$ HTST pasteurized, $\mathrm{SU}=\mathrm{UHT}$ pasteurized. Color version available online.

milk $(P<0.05)$. Although it would be expected that the $\zeta$-potential would decrease with pepsin addition, it remained relatively stable regardless of processing because the products of the pepsin digestion - casein and whey peptides - appear to have nearly the same $\zeta$-potential.

The $\zeta$-potential of the raw and the processed whole or skim milk samples increased slightly with pepsin digestion over the $60 \mathrm{~min}$ period. As shown in Figure 4 , the $\zeta$-potential of $\mathrm{HU}$ increased to $\mathrm{G}=60 \mathrm{~min}$ but maxima for the $\zeta$-potential of the other treatments were reached at varying times: for $R W$ and $P$, at $G=30$ min and for $\mathrm{H}$ and $\mathrm{HP}$, at $\mathrm{G}=15 \mathrm{~min}$. For the skim milk samples, the maximum $\zeta$-potential for SR and SP occurred at $\mathrm{G}=60 \mathrm{~min}$ and that for $\mathrm{SU}$ at $\mathrm{G}=15$ min. These maxima may represent a transition during gastric digestion in which protein hydrolysis by pepsin was nearly completed and the $\zeta$-potential was now that of the peptide products of the digestion.

After the last gastric sample digested at $60 \mathrm{~min}$ was obtained, it was mixed with SIF and bile extracts at $\mathrm{pH} 7$ to initiate intestinal digestion. The $\zeta$-potential then became negative again because the $\mathrm{pH}$ was above the isoelectric point of the rest of the protein and peptides. At this point, the bile salts may have replaced the remaining protein and peptides from the surfaces of the fat globules (van Aken, 2010). For all samples, the $\zeta$-potential decreased rapidly during the first $15 \mathrm{~min}$ $(\mathrm{I}=15 \mathrm{~min})$ because of the added pancreatin. The trypsin and chymotrypsin hydrolyzed the protein and 
peptides in the milk sample, and lipase hydrolyzed the triglyceride molecules into free fatty acid and monoglyceride. As described in Gallier et al. (2012), these lipolytic products would build at the interface and cause the $\zeta$-potential to decrease further until the rate of buildup of these products was equal to the rate of removal. Removal would occur by solubilization of the lipolytic products into phospholipid-bile salt micelles, which would ultimately be transported through the intestinal wall. The processing method influences the $\zeta$-potential by affecting the surface charges of the proteins and the fat globules (Figure 4). For example, the $\zeta$-potentials of the milk samples at $\mathrm{I}=15$ were as follows: RW and $\mathrm{H}(-42.9 \mathrm{mV}), \mathrm{P}$ and $\mathrm{HP}(-51.4 \mathrm{mV})$, and $\mathrm{HU}(-57.3 \mathrm{mV})$. For the skim milk samples, at I $=15$, the $\zeta$-potentials were SR $(-42.7)$, SP $(-38.0)$, and SU (-40.2). After $1 \mathrm{~h}$, the $\zeta$-potentials reached approximately $90 \%$ of their final values after $2 \mathrm{~h}$ of intestinal digestion: RW $(-40.4 \mathrm{mV}), \mathrm{H}(-44.7 \mathrm{mV}), \mathrm{P}$ $(-58.1 \mathrm{mV}), \mathrm{HP}(-62.6 \mathrm{mV})$, and $\mathrm{HU}(-76.9 \mathrm{mV})$. All $\zeta$-potentials then leveled off except that for HU, which continued in a downward trend. For skim milk, the final value of $\zeta$-potential for SR, SP, and SU was the same at $-44.1 \mathrm{mV}$. The $\zeta$-potentials for RW and $\mathrm{H}$ and the skim milk samples leveled off to a slightly more negative value than their starting values of approximately $-37.0 \mathrm{mV}$.

We can conclude that the differences in $\zeta$-potentials between the "native" skim milk samples and the gastrointestinal-digested skim milk samples could be due to digestion alone, resulting from breakdown of the proteins by pepsin and then trypsin or chymotrypsin to peptides with lower overall negative charge. Most of the transition can be considered complete in about $1.5 \mathrm{~h}$. For the whole milk RW and $\mathrm{H}$ samples, the $\zeta$-potentials after gastrointestinal digestion were similar to those for skim milk with digestion also completed in $1.5 \mathrm{~h}$. The $\zeta$-potentials did not show any specific interactions between the proteins and fats in either sample. However, for the RW sample, $\mathrm{d}_{32}$ increased by $1.8 \mu \mathrm{m}$ after 2 $\mathrm{h}$ of intestinal digestion, which could be an indication of coalescence of the fat globules. For H, in which homogenization causes the MFGM to adsorb casein in the absence of heat (Lee and Sherbon, 2002), $d_{32}$ after $2 \mathrm{~h}$ of intestinal digestion increased by $1.5 \mu \mathrm{m}$ and coalescence of the globules can be assumed, although the contribution of homogenization to digestibility is not apparent by the $\zeta$-potential value. This is also true for the $\mathrm{H}$ and $\mathrm{HP}$ samples. The effects of $\mathrm{P}$ or $\mathrm{HP}$ on digestibility of milk are difficult to distinguish based on the final value of $\zeta$-potential after $2 \mathrm{~h}$ of intestinal digestion. As shown in Figure 4, the zeta-potential of $\mathrm{P}$ decreased $6.3 \mathrm{mV}$ from $\mathrm{I}=15$ to $\mathrm{I}=60 \mathrm{~min}$ of intes- tinal digestion and that of HP decreased $15.5 \mathrm{mV}$ over the same time period and then increased again. Particle size increased by $1.8 \mu \mathrm{m}$ for the $\mathrm{P}$ sample and by 1.5 $\mu \mathrm{m}$ for HP, indicating coalescence of the globules.

\section{Microstructure}

The microstructures of selected milk samples during various stages of digestion are shown in Figures 6 and 7. Undigested P milk (Figure 6, top left) consisted of fat globules (stained red) ranging from 1 to $10 \mu \mathrm{m}$ in diameter in an uninterrupted protein matrix (stained green). During gastric digestion (Figure 6, top right and center), the protein matrix began to break into pieces. The protein matrix was mostly disintegrated by the start of intestinal digestion (Figure 6, bottom left), allowing the fat droplets to cluster together. Over 120 min of intestinal digestion (Figure 6, bottom right), the fat globules and remaining protein combined into small structures, as evidenced by the yellow staining in the images. The fat globules appear relatively intact although a shaded area in the center suggests coalescence of the globules. Undigested HP milk (Figure 7, top left) consisted of an uninterrupted protein matrix with fat globules $<4 \mu \mathrm{m}$ in diameter, with most being in the 0.7 to $2.0 \mu \mathrm{m}$ range. Gastric digestion appeared as described above. At the beginning of intestinal digestion (bottom left), the lipids begin to break down. However, at $\mathrm{I}=120$, it is apparent that lipid remains and the globules are larger than those in the undigested milk, with coalescence of the globules shown but also some stabilization of the globules by protein.

\section{Free Fatty Acid Release}

The release of total free fatty acids from milk during intestinal digestion is shown in Figure 8. The rate of lipolysis was fast in the first $15 \mathrm{~min}$ and then slowed because the accumulation of lipolytic products at the interface apparently prevented the pancreatic lipase from accessing the triglyceride core (Gallier and Singh, 2012). The rapid digestion led to an accumulation of lipolytic products at the surface of the fat globule, which slowed the rate of fat digestion until bile salts and phospholipids were able to solubilize the lipolytic products into micelles. Most bovine milk lipids are unsaturated fatty acids that migrate rapidly from the interface to aqueous phase and do not inhibit further digestion by pancreatic lipase ( $\mathrm{Li}$ et al., 2011).

As with studies on walnut oil and raw milk, no lag phase was observed, meaning that the bile salts efficiently displaced some pepsin-digested residual MFGM material, colipase adsorbed quickly onto the bile salt- 
covered interfacial areas, and pancreatic lipase bound to colipase and was activated within seconds after addition to the pregastric digested milk mixed with bile extracts and SIF (Gallier et al., 2012, 2013).
Compared with raw milk, homogenization significantly increased the free fatty acid release. This may be attributed to dislodging of the MFGM by homogenization, which increased the surface available to the lipase.
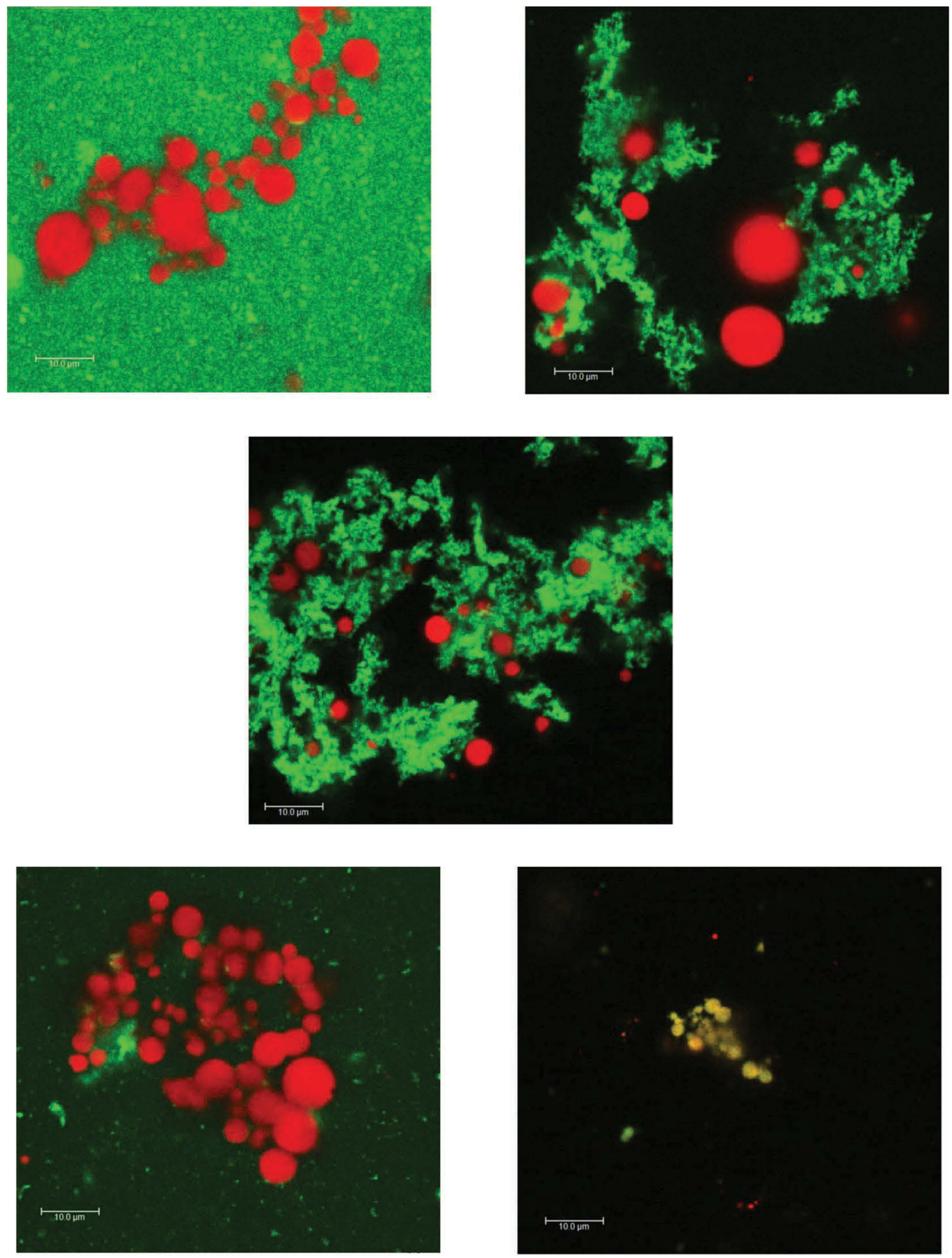

Figure 6. Confocal laser scanning microscopy images of HTST-pasteurized whole milk (P) during digestion. Areas stained green and red correspond to protein and fat, respectively; yellow areas are structures composed of protein and fat. Top left $=$ undigested milk, top right $=$ start of gastric digestion, center $=$ after $60 \mathrm{~min}$ gastric digestion, bottom left $=$ start of intestinal digestion, bottom right $=$ after 120 min intestinal digestion. Bars at lower left of each image represent $10.0 \mu \mathrm{m}$. 
Other processes such as UHT also increased the free fatty acid release, which may be because heat damaged the structure of the fat globule, allowing the enzyme to easily digest lipids.

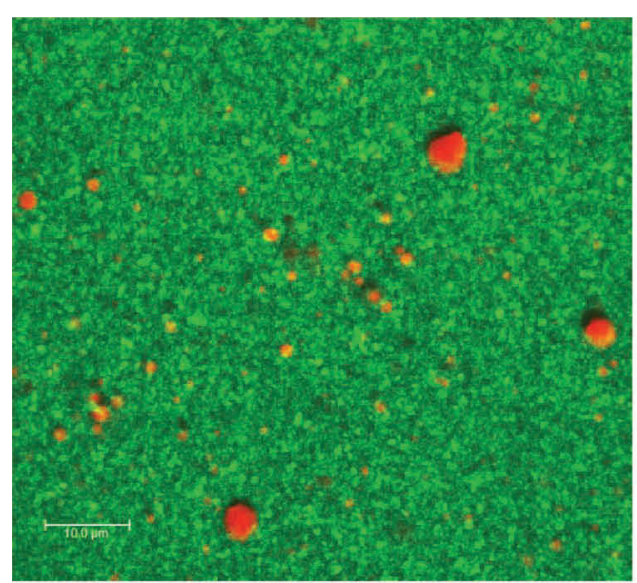

\section{Fatty Acid Profiles}

About $75 \%$ of the fatty acids in the milk were composed of myristic acid (14:0), palmitic acid (16:0), stea-

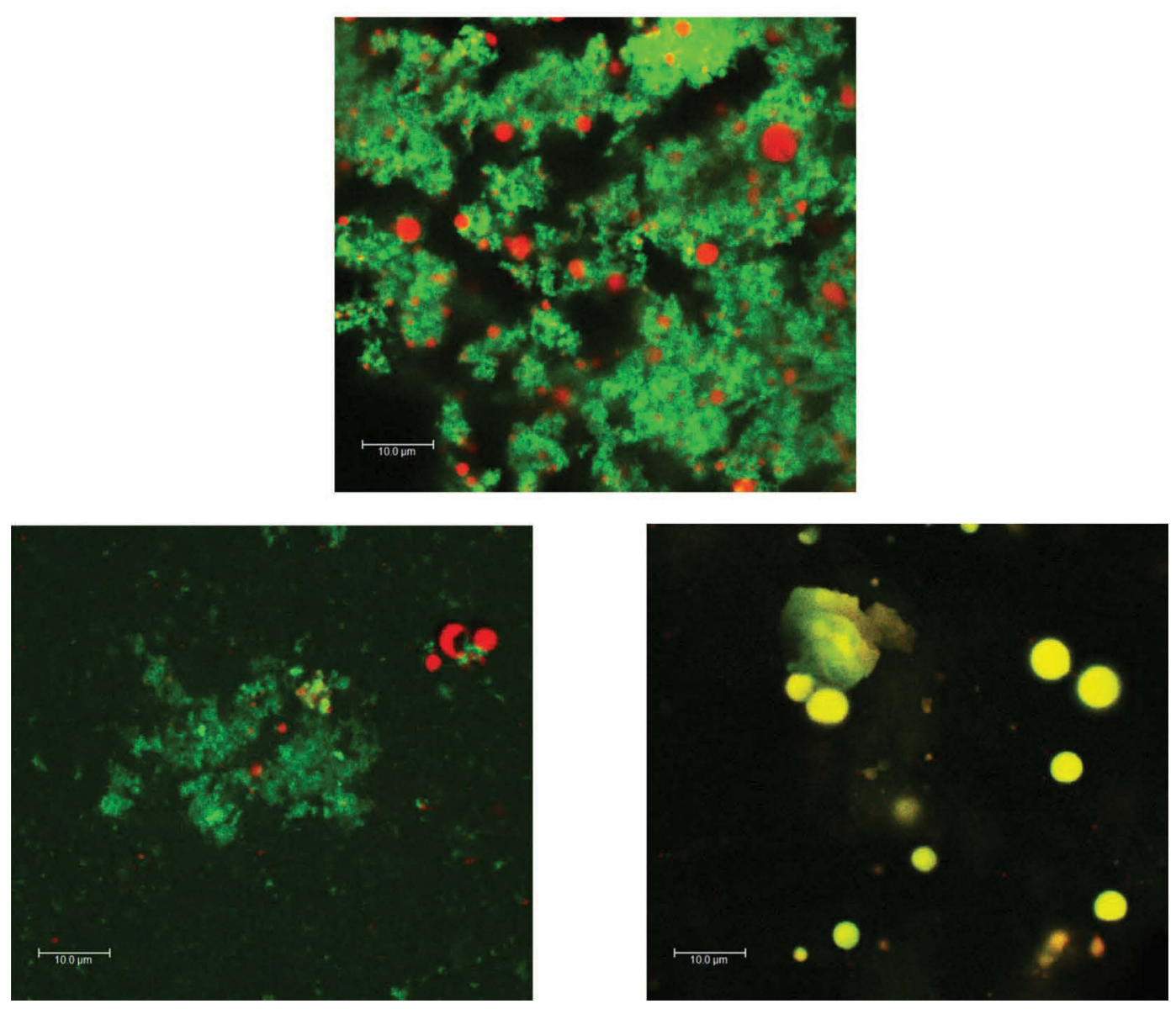

Figure 7. Confocal laser scanning microscopy images of homogenized and HTST pasteurized whole milk (HP) during digestion. Areas stained green and red correspond to protein and fat, respectively; yellow areas are structures composed of protein and fat. Top left = undigested milk, top right $=$ start of gastric digestion, center $=$ after $60 \mathrm{~min}$ gastric digestion, bottom left $=$ start of intestinal digestion, bottom right $=$ after $120 \mathrm{~min}$ intestinal digestion. Bars at lower left of each image represent $10.0 \mu \mathrm{m}$. 
Table 1. Percentages of major fatty acids in processed whole milk subjected to intestinal digestion, along with ratios of palmitic, stearic, and oleic acids to myristic acid

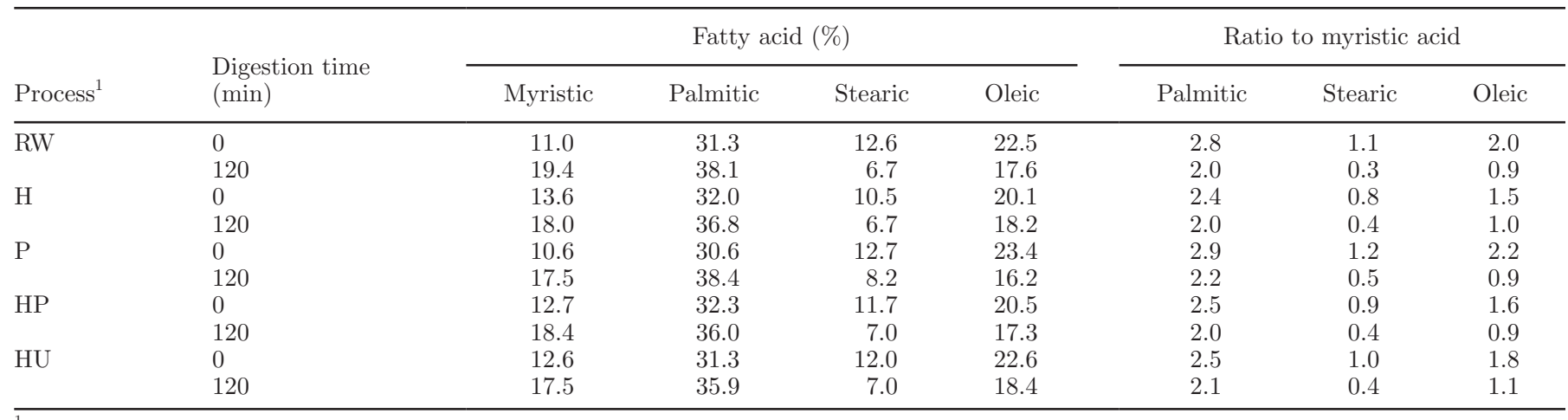

${ }^{1} \mathrm{RW}=$ raw whole milk; $\mathrm{H}=$ homogenized; $\mathrm{P}=$ pasteurized; $\mathrm{HP}=$ homogenized and pasteurized; HU = homogenized and UHT pasteurized.

ric acid (18:0), and oleic acid (18:1) (Table 1). After 120 min of intestinal digestion, the percentages of 18:0 and 18:1 decreased while the percentages of 14:0 and 16:0 went up, giving the appearance that the percentages of 14:0 and 16:0 were increasing when in fact they were decreasing at a slower rate than the others. All of the fatty acids decreased with digestion, but 18:0 and 18:1 degraded at a faster rate than 14:0 and 16:0. The ratios (Table 1) indicate that palmitic, stearic, and oleic acids decreased with digestion time at a faster rate than did myristic acid.

In cow milk, $93 \%$ of myristic acid (14:0) is found in the $s n-2$ (center) position of the triglyceride molecule (Jensen, 2002). This fatty acid is released by lipolytic enzymes at a slower rate than $18: 0$ and $18: 1 ; 84 \%$ of $18: 0$ and $79 \%$ of $18: 1$ are found at the $s n-1$ and $s n-3$ (outer) positions (Jensen, 2002). The ratio of 18:0 to 14:0 in all samples initially averaged 1.0, but after 120 min of intestinal digestion, the ratio decreased to 0.4 , meaning that the 18:0 content decreased far more than that of 14:0. The ratio of 18:1 to 14:0 started around 1.8 and ended at 1.0 after $120 \mathrm{~min}$, and the ratio of $16: 0$ to $14: 0$ went from 2.6 to 2.0 during the same time, indicating that the 16:0 and 18:1 contents also decreased greatly compared with 14:0 content. The amount of 14:0 presumably decreased as well, but at a slower rate than the other fatty acids. The type of processing did not appear to affect the fatty acid composition.

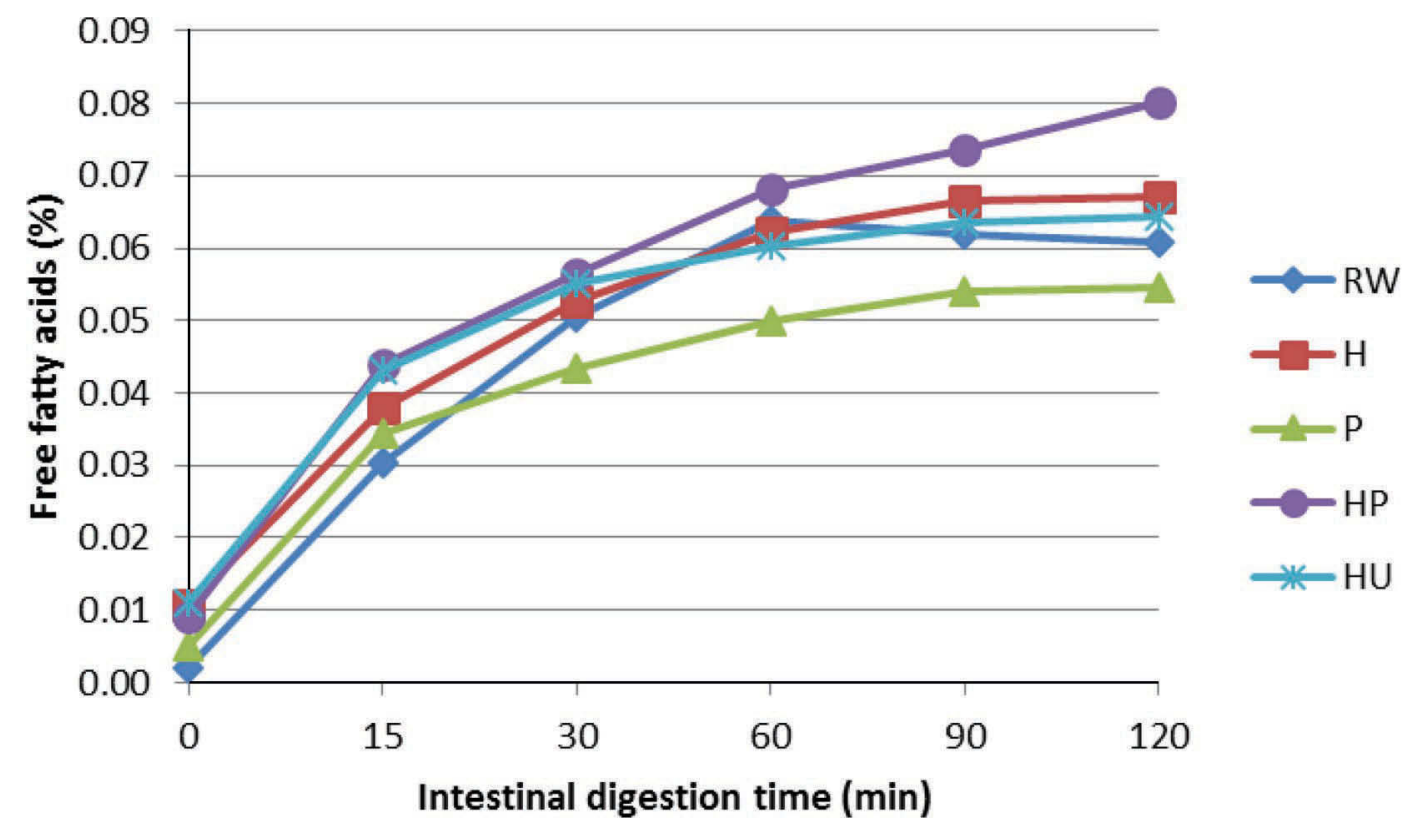

Figure 8. Free fatty acid release from 5 treatments of whole milk during $2 \mathrm{~h}$ of intestinal digestion preceded by $1 \mathrm{~h}$ of gastric digestion. $\mathrm{RW}=$ raw whole milk, $\mathrm{H}=$ homogenized, $\mathrm{P}=$ HTST pasteurized, $\mathrm{HP}=$ homogenized and HTST pasteurized, HU $=$ homogenized and UHT pasteurized. Color version available online. 


\section{Casein Phosphopeptides}

Five CPP sequences were isolated from the gastric digests and were observed in the HP or HU milk samples; one was also found in the RW sample. One fragment was $\beta$-CN $\mathrm{f}(1-16)$ and the other 4 were derivatives of $\alpha_{\mathrm{S1}}-\mathrm{CN} \mathrm{f}(110-120)$, clipped at various points, and included the sequence $\mathrm{f}(113-118)$.

In contrast, intestinal digestion yielded $31 \mathrm{CPP}$, from all 4 caseins found in milk and all types of processing methods tested except P. As with the gastric digests, many of the sequences were derivatives of the same fragments. Half of the fragments were derived from $\beta-\mathrm{CN} ; 7$ peptides were from the $\mathrm{f}(1-16)$ region and all included the $\mathrm{f}(14-16)$ segment, and 9 peptides were from the $\mathrm{f}(30-52)$ region and contained the $\mathrm{f}(34-40)$ segment. Ten peptides were derived from $\alpha_{\mathrm{S}^{-}} \mathrm{CN} ; 2$ were from the $\mathrm{f}(43-63)$ region that included the $\mathrm{f}(46-58)$ segment and 8 were from the $\mathrm{f}(104-119)$ region and included the $\mathrm{f}(113-118)$ segment. The $4 \alpha_{\mathrm{S} 2}-\mathrm{CN}$ fragments were from the $\mathrm{f}(138-148)$ region and included the $\mathrm{f}(140-146)$ segment. Only one peptide was derived from $\kappa-\mathrm{CN}, \kappa-\mathrm{CN}$ $\mathrm{f}(147-153)$.

The CPP function primarily to bind and solubilize minerals and are important in enhancing the bioavailability of calcium, zinc, and iron (Meisel and Fitzgerald, 2003; Miquel et al., 2005). Casein phosphopeptides with known mineral binding capabilities include $\alpha_{\mathrm{S1}^{-}}$ $\mathrm{CN} f(46-58), \alpha_{\mathrm{S} 1}-\mathrm{CN} \mathrm{f}(59-79), \alpha_{\mathrm{S} 2}-\mathrm{CN} \mathrm{f}(1-32), \alpha_{\mathrm{S} 2}-\mathrm{CN}$ $\mathrm{f}(55-64), \beta-\mathrm{CN} \mathrm{f}(1-25)$, and $\beta-\mathrm{CN} \mathrm{f}(33-48)$ (Meisel and Fitzgerald, 2003). Only our $\beta$-CN peptides were smaller fragments of reported mineral-binding CPP. Although none of the peptides isolated in our study contained the triple Ser-P double Glu sequence noted for the highest affinity for binding minerals (Meisel and Fitzgerald, 2003; Miquel et al., 2005), our peptides did contain Ser-P, which have potential to bind minerals. The Ser-P found at position 149 in $\kappa-\mathrm{CN}$ is located in the glycomacropeptide segment of the protein, and the binding potential of the 6-AA sequence found in our study has not yet been investigated. Other CCP that were found in our study may also be bioactive but have not been investigated yet.

\section{CONCLUSIONS}

Raw and processed milk samples were subjected to in vitro gastrointestinal digestion. Protein digestibility was improved by homogenization and by skimming the milk. Processing by UHT induced whey protein aggregation with casein or fat globules. Under gastric conditions, skim milk formed larger particles than whole milk whereas UHT reduced the particle size. The $\zeta$-potential results indicated that pasteurization and UHT process- ing increased the aggregation of fat and protein due to rupture of the MFGM. The protein matrix disintegrated during digestion, leaving aggregated fat droplets that gradually shrank in size and combined with the protein. The speed of release of free fatty acids was fastest in homogenized samples. Stearic and oleic acids degraded faster than the other fatty acids; no differences in fatty acid profiles were observed between the milk treatments. Intestinal digestion greatly increased the number of casein phosphopeptides generated. The study shows that digestion of milk varies depending on the way it is processed.

\section{ACKNOWLEDGMENTS}

We acknowledge the technical contributions by other co-workers at USDA-ARS-ERRC, Wyndmoor, Pennsylvania: Audrey Thomas-Gahring for nitrogen analysis, James J. Shieh for milk composition analyses, Julia Fischer for SDS-PAGE preparation, Brien Sullivan for sample extractions, and Joseph Uknalis for performing confocal microscopy. We also thank Phoebe Qi for useful discussions and Alberto Nunez for isolating and sequencing the casein phosphopeptides. Mention of trade names or commercial products in this article is solely for the purpose of providing specific information and does not imply recommendation or endorsement by the USDA. This project was funded under Project 1935-41000-087 "Sustainable strategies to lower the environmental and economic impacts of food processing using fluid milk as a template." This project is a part of National Program 306, Quality and Utilization of Agricultural Products.

\section{REFERENCES}

Christie, W. W. 2003. Lipid Analysis. 3rd ed. Oily Press, Bridgewater, UK.

Claeys, W. L., S. Cardoen, G. Daube, J. De Block, K. Dewettinck, K. Dierick, L. De Zutter, A. Huyghebaert, H. Imberechts, P. Thiange, Y. Vandenplas, and L. Herman. 2013. Raw or heated cow milk consumption: Review of risks and benefits. Food Contr. 31:251-262.

Codex Committee on Milk and Milk Products. 1999. Heat treatment definitions. Accessed Sep. 21, 2015. ftp://ftp.fao.org/codex/ Meetings/CCMMP/ccmmp4/mm00_15e.pdf.

Corredig, M., and D. G. Dalgleish. 1996a. Effect of temperature and $\mathrm{pH}$ on the interactions of whey proteins with casein micelles in skim milk. Food Res. Int. 29:49-55.

Corredig, M., and D. G. Dalgleish. 1996b. Effect of different heat treatments on the strong binding interactions between whey proteins and milk fat globules in whole milk. J. Dairy Res. 63:441-449.

Douglas, F. W., Jr., R. Greenberg, H. M. Farrell Jr., and L. F. Edmondson. 1981. Effects of ultra-high temperature pasteurization on milk proteins. J. Agric. Food Chem. 29:11-15.

Farrell, H. M., Jr., and F. W. Douglas Jr. 1983. Effects of ultra-hightemperature pasteurization on the functional and nutritional properties of milk proteins. Kieler Milchwirtsch. Forschung. 35:345-356.

FDA (Food and Drug Administration). 2013. U.S. Department of Health and Human Services. Public Health Service. Grade "A", Pasteurized Milk Ordinance; 2013 revision. Accessed 
Feb. 3, 2016. http://www.idfa.org/news-views/headline-news/ article/2014/03/19/2013-pmo-and-related-documents-nowavailable-online.

Gallier, S., and H. Singh. 2012. Behavior of almond oil bodies during in vitro gastric and intestinal digestion. Food Funct. 3:547-555.

Gallier, S., H. Tate, and H. Singh. 2013. In vitro gastric and intestinal digestion of a walnut oil body dispersion. J. Agric. Food Chem. 61:410-417.

Gallier, S., A. Ye, and H. Singh. 2012. Structural changes of bovine milk fat globules during in vitro digestion. J. Dairy Sci. 95:3579 3592.

Garcia-Risco, M. R., M. Ramos, and R. Lopez-Fandino. 2002. Modifications in milk proteins induced by heat treatment and homogenization and their influence on susceptibility to proteolysis. Int Dairy J. 12:679-688.

Jensen, R. G. 2002. The composition of bovine milk lipids: January 1995 to December 2000. J. Dairy Sci. 85:295-350.

Lee, S. J., and J. W. Sherbon. 2002. Chemical changes in bovine milk fat globule membrane caused by heat treatment and homogenization of whole milk. J. Dairy Res. 69:555-567.

Li, Y., M. Hu, and D. J. McClements. 2011. Factors affecting lipase digestibility of emulsified lipids using an in vitro digestion model: Proposal for a standardised pH-stat method. Food Chem. 126:498505.

Meisel, H., and R. J. Fitzgerald. 2003. Biofunctional peptides from proteins: Mineral binding and cytomodulatory effects. Curr. Pharm. Des. 9:1289-1295.

Michalski, M.-C., and C. Januel. 2006. Does homogenization affect the human health properties of cow's milk? Trends Food Sci. Technol. $17: 423-437$.

Miquel, E., J. A. Gómez, A. Alegría, R. Barberá, R. Farré, and I. Recio. 2005. Identification of casein phosphopeptides released after simulated digestion of milk-based infant formulas. J. Agric. Food Chem. 53:3426-3433.

Mun, S., E. A. Decker, and D. J. McClements. 2007. Influence of emulsifier type on in vitro digestibility of lipid droplets by pancreatic lipase. Food Res. Int. 40:770-781.

Smith, T. P. 2010. Got E. coli? Raw milk's appeal grows despite health risks. Accessed Sep. 21, 2015. http://www.scientificamerican.com/ article/raw-milk-debate/.

Tomasula, P. M., and M. F. Kozempel. 2004. Flow characteristics of a pilot-scale high temperature, short time pasteurizer. J. Dairy Sci. $87: 2761-2768$

US Pharmacopeia. 2012. Simulated gastric fluid. Page 5778 in The National Formulary 30. Vol. 1. US Pharmacopeia Board of Trustees, Rockville, MD.

van Aken, G. A. 2010. Relating food emulsion structure and composition to the way it is processed in the gastrointestinal tract and physiological responses: What are the opportunities? Food Biophys. 5:258-283.

Wada, Y., and B. Lönnerdal. 2014. Effects of different industrial heating processes of milk on site-specific protein modifications and their relationship to in vitro and in vivo digestibility. J. Agric. Food Chem. 62:4175-4185.

Walzem, R. L., C. J. Dillard, and J. B. German. 2002. Whey components: Millennia of evolution create functionalities for mammalian nutrition: What we know and what we may be overlooking. Crit. Rev. Food Sci. Nutr. 42:353-375.

Ye, A. Q.. J. Cui, and H. Singh. 2011. Proteolysis of milk fat globule membrane proteins during in vitro gastric digestion of milk. J. Dairy Sci. 94:2762-2770. 